Revista de Psicología Vol. 33 (1), 2015 (ISSN 0254-9247)

\title{
Consenso y divergencias en las representaciones sociales de la dirigencia política
}

\author{
Cynthia María Torres Stöckl ${ }^{1}$ y Elena Mercedes Zubieta ${ }^{2}$ \\ Universidad Nacional de Tucumán ${ }^{1}$, Universidad de Buenos Aires ${ }^{2} y$ \\ CONICET $T^{2}$ - Argentina
}

Se analiza descriptivamente la faceta consensual y diferencial de las representaciones sociales sobre la dirigencia política, en base a una muestra de estudiantes de la Facultad de Psicología y en la Facultad de Filosofía y Letras de la Universidad Nacional de Tucumán (UNT)-Argentina. Los resultados muestran un universo representacional en tensión caracterizado por componentes nucleares contrarios: Liderazgo y Representación versus Poder y Corrupción; y por dimensiones opuestas: Características/Aspectos Políticos Positivos versus Características/Aspectos Políticos Negativos, así como por conglomerados primordiales concordantes con estas últimas. Se observan también diferencias en función de variables como año de cursado, militancia en agrupaciones políticas estudiantiles, antecedentes de participación política en la Universidad y cargos/figuras políticas de diversa índole.

Palabras clave: representaciones sociales, dirigencia, consenso, divergencias

\section{Consensus and divergence in the social representations of political leadership}

The aim of this paper is to analyze descriptively the consensual and differential dimensions of political leadership social representations, based on a convenience sample composed of Psychology, Philosophy and Humanities college students from Tucumán National University, Argentina. Results show a representational universe in tension characterized by opposite nuclear components: Leadership and Representation versus Power and Corruption, as well as opposite dimensions: Features / Positive Political Aspects versus Features / Negative Political Aspects, as well as two relevant clusters consistent with the latter two. Differences are also observed when analyzing variables such as: year in college, student's political group membership, university political involvement and background / types of political figures. Keywords: Social representations, leadership, consensus, divergences

1 Licenciada en Psicología y Auxiliar docente, Facultad de Psicología, Universidad Nacional de Tucumán (UNT). Dirección postal: San Lorenzo 3908. San Miguel de Tucumán. Argentina. Código postal 4000. Contacto: cynthiatorresstockl@hotmail.com

2 Doctora en Psicología por la Universidad del País Vasco (UPV), Profesora Adjunta Regular de la Universidad de Buenos Aires (UBA) e investigadora independiente CONICET. Dirección postal: General Juan Lavalle 2353.Ciudad Autónoma de Buenos Aires. Argentina. (C1052AAA). Contacto: ezubieta@psi.uba.ar 

La vigencia de los problemas económicos y sociales, así como la frustración cada vez mayor respecto a las instituciones del Estado en general, han llevado a un desencanto de la esfera pública (Habermas, 1992), siendo la arena política donde se toman decisiones acerca de la vida en común y se asumen responsabilidades por ellas. La corrupción, los intereses egoístas, la desconfianza, la división entre la omnipotencia del poder y la impotencia de las personas sometidas al mismo, y la ley como fuente de mensajes ambiguos, constituyen nociones centrales que dan sentido al mundo político moderno (Jovchelovitch, 2000).

Wagner y Hayes (2011) afirman que los contornos de la realidad colectiva e individual resultan de la existencia de condiciones globales y de construcciones que elaboran las personas y colectividades, quienes atribuyen a lo existente múltiples sentidos, pesos y estructuras. Es así que las representaciones devienen en un constructo que abarca virtualmente los procesos intermedios de articulación entre niveles de análisis macro y micro, pudiendo ser comprendidas como un mapeo o traducción de las condiciones del medio social más amplio en disposiciones individuales que se distribuyen y comparten grupalmente.

El significado, las cualidades y la forma que asume la vida pública en diferentes sociedades ocasionan consecuencias concretas en las características que adopta el conocimiento social que allí tiene lugar. Como espacio compuesto por instituciones específicas, rituales y significados, este es el ámbito en donde las representaciones se generan, se transmiten y se transforman, al mismo tiempo que este se convierte en un objeto propicio acerca del cual es posible desarrollar representaciones que, como factores claves contribuyen en sí mismas a su propia constitución (Jovchelovitch, 2000).

Lozada Santeliz (2000) explicita que, desde la mirada psicosocial, propia de las representaciones, el desafío cultural de la democracia exige la comprensión tanto de las causas estructurales de sus dificultades y sus 
transiciones, así como el análisis de los sistemas simbólicos e imaginarios que en torno a ella se articulan. Se trata, entonces, de lograr una aproximación a la dimensión histórica, económica, cultural y subjetiva de las crisis políticas, a través de las cuales es posible interpretarlas en toda su magnitud y complejidad. En este contexto, considerar las formas de acción, juicios, sentimientos y valoraciones sostenidos por la gente común, resulta de gran utilidad en la medida en que permiten informarnos y orientarnos sobre cómo es vivido dicho universo por parte de los propios sujetos (Villarroel, Brito \& De Armas, 2004).

Boudon y Bourricaud (1994) señalan al respecto que el valor de estudiar las creencias portadas por los actores sociales reside en que el comportamiento, la acción individual o colectiva, se asocia fuertemente con el pensamiento sobre un determinado estado de cosas. En calidad de transcripciones subjetivas y personales de los objetos que pueblan el universo social, las representaciones constituyen así factores que guían y motivan el comportamiento (Abric, 1971), por lo que de esta manera es posible pensar a las teorías del sentido común sobre la política como una herramienta fundamental para comprender las fuerzas que influyen en el desarrollo de la participación de idéntica naturaleza.

Como indican Villarroel y De Armas (2005, p. 22):

De modo general, las representaciones sociales constituyen categorías cognoscitivas relativamente coherentes y estables que nos sirven para conocer, interpretar y actuar sobre la realidad. Cuando estas configuraciones socialmente generadas y compartidas se refieren específicamente al sistema político y a las experiencias democráticas de una sociedad, pueden denominarse cultura o representaciones políticas. Empíricamente, este concepto describe y agrega lo que las personas sencillas piensan, valoran, o imaginan acerca de las instituciones y las prácticas políticas, así como sobre sus propias experiencias, conductas y orientaciones políticas.

Mendoza y Camino (2000) establecen que comúnmente el espacio político es reducido al funcionamiento formal del sistema y a la relación legal y abstracta del individuo con este, excluyéndose de la definición a las relaciones informales, concretas y subjetivas, desconsiderándose 
precisamente que este espacio se enriquece a partir de distintas formas de evaluar, sentir y percibir a la política en general. Enfatizando ambos planos, Camino, Lima y Torres (1997) afirman que este campo incluye por lo tanto los conflictos por medio de los cuales la política se presenta objetivamente, y se representa subjetiva e intersubjetivamente. Tomando los aportes de Braud (1991), Villarroel (2001), aclara de forma concluyente que la explicación de lo político concierne también a aspectos simbólicos del funcionamiento democrático, puesto que la actividad política, es ante todo, un trabajo de representaciones.

Concebidas como una red de imágenes, conceptos interactivos, cuyos contenidos evolucionan continuamente en el tiempo y el espacio (Moscovici, 1988, p. 220), estas representaciones constituyen una forma específica de conocimiento social que ha sufrido variaciones y diversificaciones, producto de un trabajo de adaptación a una sociedad y cultura contemporáneas, caracterizadas en sí mismas por el desarrollo de las telecomunicaciones, la informática, la ciencia, el flujo exponencial de la información y la mutación constante de los escenarios políticos, económicos y sociales (González Pérez, 2006).

De acuerdo con Wagner, Duveen, Verna y Themel, (2000) las formas de pensamiento y representaciones dentro de la cultura en sociedades contemporáneas y la propia cultura contemporánea, no se muestran generalmente en equilibrio, sino más bien en permanente flujo y transformación, siendo en este medio particular donde el pensamiento de sentido común adopta un carácter llamativamente plural, mutifacético y heterogéneo. Al respecto Jovchelovitch (2001) explica que en los mundos no tradicionales la novedad/diferencia juegan un rol crucial, así como el constante cuestionamiento/desafío a las tradiciones y la coexistencia/competencia equitativa de visiones del mundo, por lo que es la esfera pública la que respalda la emergencia de discursos múltiples, en la medida en que en ella se cocinan representaciones atravesadas por un sinnúmero de matices colectivos derivados de la reflexión acerca de realidades particulares que tienen lugar en el marco de las tendencias globalizantes de una modernidad tardía. En la misma línea, Bourdieu (1976) esboza que las sociedades más desarrolladas, 
sean ortodoxas o heterodoxas, incluyen el conocimiento y el reconocimiento de la posibilidad de convicciones diferentes o antagónicas, resultando justamente esta posibilidad de experiencias y saberes contradictorios un prerrequisito para la emergencia de una forma de discurso colectivo que permite discrepancias en el sentido común cotidiano.

Para Jodelet (1989), las representaciones sociales hacen referencia a la actividad mental que los individuos y grupos despliegan con el fin de fijar su posición en relación con situaciones, acontecimientos, objetos y comunicaciones que les conciernen. En este sentido, estas constituyen singulares maniobras de apropiación y posicionamiento por parte del cuerpo social en torno a temas, hechos y fenómenos portadores de gran relevancia y centralidad. Impregnados por valores e ideologías heterogéneas y heteróclitas de la vida cotidiana de los conjuntos, estratos y clases sociales en las que conviven, los ciudadanos evalúan la política con la subjetividad propia de los colectivos a los cuales pertenecen (Bourdieu, 1992; Gramsci, 1987). De esta manera, las representaciones de la política permiten indefectiblemente tomar conocimiento sobre la existencia de cualidades significativas sobre el objeto en consideración, las que dependerán del pensamiento particular de cada grupo (Rodríguez Cerda, Díaz Gómez \& Mendoza Romero, 1997).

Siguiendo esta lógica, Banchs (1994) aclara que los contenidos representacionales reflejan no solo los substratos culturales de una sociedad y de un momento histórico, sino también de una determinada posición en la estructura social. En virtud de esta apreciación, Doise (1993) reconoce la existencia de indicadores que organizan un universo simbólico común, en relación con el cual los individuos o subgrupos toman posiciones derivadas de sus inserciones específicas en una serie de relaciones. De modo que la centralidad de los elementos que definen una representación no está primariamente determinada por el consenso, sino por el marcaje social como proceso a través del cual ciertas condiciones sociales van zurcidas a las operaciones cognitivas en el trato con objetos de interés.

Por consiguiente, es posible hablar de una participación diferente en el conocimiento culturalmente compartido, en tanto el contenido, 
estructura y sofisticación de las representaciones dependen de las posturas individuales y grupales correlativas a los lugares ocupados dentro del entramado inherente a una sociedad, permitiendo esto, la existencia de diferentes configuraciones respecto a un mismo campo social (Wagner \& Hayes, 2011).

Postulando que el pensamiento de sentido común no solo implica compartir significados comunes sino también disentimientos y oposiciones, Rodríguez Salazar (2002), insiste en la importancia de definirlo no solo como generador de acuerdos sino también como medio de diferenciación social, por lo que un objeto idéntico puede ser significado de manera disímil por diferentes grupos sociales. Desde esta perspectiva, Nateras Domínguez, Mendoza Romero y Angulo Reyes, (1999) aclaran que si bien el contenido de cada esquema o modelo figurativo representacional tiende a caracterizarse en forma similar, hay diferencias en sus grados de estructuración, es decir, que en un espacio y tiempos determinados la socio-génesis de los contenidos es común aunque diferentes grupos sociales no necesariamente los estructuran de manera equivalente y no presentan el mismo sentido.

A pesar de ser elaboraciones comunes que se desprenden de modalidades de pensamiento compartidas, las representaciones, entre ellas, las referidas al dominio de la política y sus elementos, no excluyen sino, por el contrario, admiten el conflicto y la contradicción. Las creencias, las actitudes, los valores que conforman dichas representaciones se ordenan en un patrón coherente, pero ello no significa que todos los estratos o conjuntos sociales comparten la misma cultura, o que este patrón está distribuido uniformemente en la población (Diamond, 1994). De hecho, la diversidad de opiniones respecto al ámbito político proviene de múltiples maneras de tomar posición sobre dimensiones subyacentes que parecen ser universales (Spini, 1997), por lo que la existencia de principios conjuntos en tal espacio no implica necesariamente homogeneidad, sino posturas diferenciales en torno a esas mismas dimensiones.

Desde las bases fundadas por Moscovici en 1961 en su estudio sobre el Psicoanálisis, varias escuelas -inscriptas en la Psicología social Europea - han propuesto enfoques teóricos y estrategias metodológicas 
para abordar la vida y pensamientos ordinarios, brindando a las representaciones sociales un estatus especial como materia de investigación. Una de las vertientes más destacadas es la perspectiva estructural surgida en Aix en Provence (Francia) entre las décadas del 1970 y 1980. De corte experimentalista, esta corriente parte de una concepción del fenómeno representacional en términos de estructuras, es decir de sistemas de unidades interconectadas cuyo funcionamiento está regulado por leyes (Wachelke, 2012).

Derivada de la obra originaria mencionada, la teoría del núcleo central (Abric, 1976) constituye el aporte más importante al estudio de las representaciones sociales y a su estructura, en tanto propone la existencia de dos sistemas de elementos cualitativamente diferentes: un núcleo central y una periferia. La hipótesis de centralidad vigente en el pensamiento de Moscovici, ha sido reforzada por todos sus seguidores quienes valoran la importancia de la matriz representacional, otorgándole diferentes denominaciones como: núcleo organizador (Grize, Verges y Silem, 1987), núcleo estructural latente (De Rosa, 1987), núcleo duro (Mugny y Carugati, 1985).

El sistema o núcleo central está compuesto por uno o unos pocos elementos cognitivos que son responsables de la estabilidad, la rigidez y el carácter consensual de la representación. Estos elementos, que pueden ser creencias, opiniones, actitudes, se encuentran ligados a la memoria colectiva y a la historia del grupo, y son por ende resistentes a los cambios y pocos sensibles a la modificación del contexto social inmediato. Entre las funciones propias de este sistema se destacan específicamente la generación del sentido global de la representación y la organización de toda su estructura (Abric, 2001).

De esta forma, el núcleo central representa el corazón de las representaciones, remitiendo a aquellos componentes permanentes, compartidos y abstractos, portadores de un gran fuerza simbólica en tanto naturalizados y legitimados a nivel social, adoptando una naturaleza claramente incondicional y no negociable (Flament, 2001). Menos sensibles y resistentes a las circunstancias sociales próximas, estos elementos se encuentran vinculados de manera estrecha con la ideología, 
el pasado, la sociedad y la cultura, de los que se desprenden las creencias, normas y valores portados por los sujetos y grupos, siendo por esto en esencia normativos (Abric, 1993).

El sistema periférico está compuesto por todos los otros elementos de la representación, los cuales son responsables de la movilidad, flexibilidad y diferencias entre individuos. Permite la integración de las experiencias individuales y se apoya en la evolución, las contradicciones y la heterogeneidad del grupo. A diferencia del sistema central, este es más sensible al contexto inmediato. Entre las funciones propias de este sistema se destacan específicamente la adaptación del contenido representacional a situaciones concretas, la regulación del mismo en base a las evoluciones del contexto, y la defensa de la matriz nuclear, a modo de un paragolpes (Abric, 2001, Flament, 1987), integrando información nueva y contradictoria proveniente del entorno social.

De esta manera, la periferia remite a aquellos componentes inestables, heterogéneos y concretos, en tanto relacionados con experiencias individuales, así como con el influjo de circunstancias sociales próximas, asumiendo características condicionales y situacionales (Flament, 2001). Constituyendo una zona intermedia o interface entre el núcleo figurativo y la realidad del momento en la que las representaciones se configuran, sustentan y realizan a sí mismas, los elementos periféricos son claramente funcionales (Abric, 1993).

Con base en la hipótesis de una polifasia cognitiva formulada por Moscovici (2003), esta escuela, al proponer una estructura jerárquica ordenada de dependencia mutua provista de elementos cognitivos, creencias y actitudes, con distintos niveles de importancia entre los que se tejen relaciones de complementariedad e indisociabilidad, intenta dar cuenta de la complejidad del fenómeno representacional, que hace que estas sean estables y móviles, rígidas y flexibles, consensuales, pero también marcadas por fuertes diferencias interindividuales.

Estimando la importancia atribuida a la teoría analizada en la aproximación a temáticas con notable envergadura como es el caso de la política, se pretendió en esta ocasión identificar y describir el contenido, la estructura y las dimensiones latentes y los conglomerados de las representaciones 
sociales acerca de la dirigencia política, a partir de una investigación con estudiantes de la Universidad Nacional de Tucumán (UNT)- Argentina. Se indagó asimismo en sus posibles diferencias en función de variables sociodemográficas tales como la edad, el sexo, la facultad, la disciplina de formación y el año de cursado; y en función de variables psicosociales, como la militancia estudiantil universitaria, la ocupación de cargos de representación estudiantil universitaria, el ejercicio del derecho a voto en elecciones de representantes estudiantiles universitarios, la posesión de antecedentes de participación y el conocimiento de aspectos inherentes a la vida política institucional. Finalmente, se examinó en sus posibles diferencias en función de cargos/figuras políticas de diversa índole.

\section{Método}

El presente es un estudio transversal y exploratorio.

\section{Participantes}

A partir de un muestreo intencional, se identificaron 431 estudiantes que asisten a la Facultad de Psicología $(59.6 \%, \mathrm{n}=257$ ) y a la Facultad de Filosofía y Letras $(40.4 \%, \mathrm{n}=174)$ de la Universidad Nacional de Tucumán (UNT)-Argentina, con un rango de edad entre los 19 y 54 ańos. La edad promedio es de 24.05 ańos $(D E=3.92)$. La variable edad se re-categorizó en dos grupos: el primero de 19 a 25 ańos, representando el $73.1 \%(n=315)$ de la muestra y el segundo de 26 a 54 ańos representando el 26.9\% $(n=116)$ de la misma, denominándoselos adultos jóvenes y adultos medios respectivamente. Un $83.1 \%$ $(n=358)$ eran mujeres y un $16.9 \%(n=73)$ eran hombres. El $59.6 \%$ $(n=257)$ cursaban disciplinas destinadas a dar cuenta sobre aspectos del Pensamiento y Comportamiento Humano (Psicología y Filosofía), el 3.5\% $(n=15)$ disciplinas orientadas a cuestiones exclusivamente Pedagógicas (Ciencias de la Educación, Letras, Inglés, Francés), y el $36.9 \%$, ( $\mathrm{n}=159)$ disciplinas abocadas a la Organización social (Trabajo social, Historia, Geografía, Ciencias de la Comunicación). 
Un 34.3\% ( $n=148)$ eran alumnos que cursaban el tercer año de su carrera, un $35.5 \%(n=153)$ el cuarto y un $30.2 \%(n=130)$ el quinto. El $6.0 \%(n=26)$ pertenecía a agrupaciones políticas estudiantiles universitarias y el $94.0 \%(n=405)$ no formaba parte de las mismas. Un $62.2 \%(n=268)$ expresó poseer amigos, parientes o ambos comprometidos en actividades políticas dentro de la Universidad, mientras el $37.8 \%$ $(n=163)$ todo lo contrario. El 1.2\% $(n=5)$ desempeñaba tareas de representación estudiantil universitaria y el $98.8 \%(n=426)$ no lo hacía. Un $94.0 \%(n=405)$ ejercía su derecho a voto en elecciones de estudiantes en la Universidad y un $6.0 \%(n=26)$ no ejercía tal derecho. Casi la mitad de la muestra se encontraba Informada correctamente sobre aspectos básicos de la vida política institucional $(49.9 \%, n=215)$, mientras que un poco menos estaba Medianamente Informada (39.9\%, $n=172)$ y en una medida menor Desinformada $(10.2 \%, n=44)$. La variable conocimiento político universitario fue medida a través de una escala compuesta por 8 reactivos: (a) Nombre de agrupaciones políticas estudiantiles existentes en la UNT, (b) Nombre completo del actual Rector de la UNT, (c) Tiempo de duración de mandato del actual Rector de la UNT, (d) Nombre completo del actual Decano de la Facultad de pertenencia, (e) Tiempo de duración del mandato del actual Decano de la Facultad de pertenencia, (f) Nombre de la agrupación política que ganó las últimas elecciones de Centro de estudiantes de la Facultad de pertenencia, (g) Frecuencia de realización de las elecciones del Centro de estudiantes de la Facultad de pertenencia, (h) Frecuencia de realización de las elecciones de Consejeros estudiantiles universitarios de la Facultad de pertenencia. Los datos proporcionados fueron puntuados en dos posiciones Incorrecta y Correcta, confeccionándose un índice de conocimiento político integrado por tres categorías: 1-Desinformados (0 a 2 respuestas correctas), 2-Medianamente Informados (3 a 5 respuestas correctas) e 3-Informados (6 a 8 respuestas correctas).

\section{Medidas e instrumentos de medición}

El cuestionario utilizado fue de formato auto-administrado y estuvo integrado por la técnica descripta a continuación, y por 
preguntas referidas a datos s ociodemográficos, psicosociales y a cargos/ figuras políticas asociadas al dirigente politico.

\section{Cuestionario de caracterización}

Se utilizó un Cuestionario de caracterización en calidad de técnica enfocada en las características estructurales de la representación social (Abric, 2003) para identificar la estructura representacional mediante sucesivas aproximaciones a través de un conjunto de recursos, respetando los pasos correspondientes al acercamiento pluri-metodológico. La utilidad de esta técnica para la identificación de la estructura representacional, ha sido demostrada en estudios como los realizados por Guimelli, (1988), Larrañaga, Vergés y Valencia, (2007), y Moliner (1994). Se trata de un método de jerarquización de ítems en la variante elecciones sucesivas por bloques. Promovido por Flament (2001) y basado en la hipótesis de una jerarquización colectiva de temas, este método tiene como fin identificar aquellos elementos que tienen una fuerte saliencia a la hora de representar un objeto de interés científico.

El concepto de saliencia es esencialmente utilizado para indagar la importancia que los sujetos atribuyen a los componentes representacionales, teniendo en cuenta que algunos son considerados por ellos como más importantes mientras que otros en menor medida. Por lo tanto es posible establecer que cuanto más relevante es un elemento, mayor es su saliencia (Vergés, 2001). Abric (2003) justifica la utilización de este instrumento, recordando que al ser el núcleo central aquel que otorga el significado de la representación, es posible considerar que un elemento nuclear, posee la propiedad de mostrarse como muy característico respecto a otros elementos.

\section{La técnica consta de dos partes:}

Primera parte: donde a partir de pre-encuesta se conocen las categorías/temas puntuales de la representación (es decir las dimensiones asociadas al objeto), así como las palabras utilizadas al interior de cada categoría/tema. En este caso se implementaron categorías asociadas 
libremente al término inductor: dirigente político, confeccionadas en un estudio previo. En esa oportunidad, se aplicó un Test de evocación jerarquizada (Abric, 2003; Vergés, 1995), a una muestra de 426 estudiantes con rasgos similares a los del grupo analizado en esta ocasión. A partir de dicho término, se obtuvieron 1646 palabras ubicadas en una jerarquía u orden de importancia (1 más importante a 4 menos importantes). Siguiendo el criterio de proximidad semántica se crearon 55 categorías, utilizándose de manera exclusiva 29 con frecuencia igual o superior a 15 , equivalentes al $89.4 \%$ del corpus total.

En base al cruce entre la frecuencia media de evocación (51) y una media de rangos medios de importancia (2.5), dichas categorías fueron ordenadas en un Cuadrante de cuatro casas (Tabla 1).

Casa 1 o cuadrante superior izquierdo — constituido por las categorías: Corrupción, Representación, Liderazgo, Poder y Ambición-, corresponde al núcleo central o figurativo de las representaciones sociales, siendo los elementos más frecuentes y más importantes. En esta área se encuentran los términos superiores a la frecuencia media de evocación e inferiores a la media de los rangos medios de importancia calculada. Estos componentes nucleares son los más significativos y eventualmente están acompañados de elementos sin gran valor significativo los que constituyen sinónimos o prototipos asociados al objeto de la representación (Abric, 2003, p. 64).

Casa 2 o cuadrante superior derecho - integrado por las categorías: Guía, Mentira y Puntero-, corresponde a la primera periferia o periferia próxima al núcleo, siendo los elementos más frecuentes y menos importantes. En esta zona se ubican los términos superiores a la frecuencia media de evocación y superiores a la media de los rangos medios de importancia estimada. Estos elementos periféricos son los de mayor relevancia y al igual que la zona de contraste, resultan adyacentes, y complementarios del núcleo figurativo, representando una zona fluctuante, ambigua, potencialmente desequilibrante por cuanto se compone de elementos en tránsito que con el tiempo pueden pasar a constituir la matriz nuclear o a reforzar el sistema periférico (Abric, 2003; Flament, 1994; Vergés, 1992). 


\section{Tabla 1}

Cuadrante de cuatro casas representaciones sociales del Dirigente politico

\begin{tabular}{|c|c|c|c|c|c|c|}
\hline \multirow[t]{2}{*}{$\begin{array}{l}\text { Rango } \\
\text { Frecuencia }\end{array}$} & \multicolumn{3}{|c|}{$\begin{array}{l}\text { Rang } \leq 2.5 \\
\text { (Rango de importancia) }\end{array}$} & \multicolumn{3}{|c|}{$\begin{array}{l}\text { Rang }>2.5 \\
\text { (Rango de importancia) }\end{array}$} \\
\hline & \multicolumn{3}{|c|}{ NUCLEO CENTRAL } & \multicolumn{3}{|c|}{ PRIMERA PERIFERIA } \\
\hline \multirow{6}{*}{$\begin{array}{l}f>51 \\
\text { (frecuencia } \\
\text { evocación) }\end{array}$} & PALABRA & Frecuencia & Rango & PALABRA & Frecl & ia Rango \\
\hline & Corrupción & 165 & 2.4 & Guía & 131 & 2.6 \\
\hline & Representación & 145 & 2.1 & Mentira & 125 & 2.7 \\
\hline & Liderazgo & 142 & 2.0 & Puntero & 55 & 2.7 \\
\hline & Poder & 116 & 2.4 & & & \\
\hline & Ambición & 54 & 2.4 & & & \\
\hline \multirow{14}{*}{$\begin{array}{l}f \leq 51 \\
\text { (frecuencia } \\
\text { evocación) }\end{array}$} & \multicolumn{3}{|c|}{ ZONA DE CONTRASTE } & \multicolumn{3}{|c|}{ SEGUNDA PERIFERIA } \\
\hline & PALABRA & Frecuencia & Rango & PALABRA & Frecl & ia Rango \\
\hline & Compromiso & 51 & 2.5 & Sociedad & 46 & 2.6 \\
\hline & Política & 50 & 2.3 & Gobierno & 34 & 2.6 \\
\hline & Capacitación & 28 & 2.5 & Campañas & 30 & 2.7 \\
\hline & Manipulación & 26 & 2,5 & Lucha & 25 & 2.8 \\
\hline & Ideales & 20 & 2.1 & $\begin{array}{l}\text { Oportu- } \\
\text { nismo }\end{array}$ & 24 & 2.9 \\
\hline & Protesta & 21 & 2.3 & Honestidad & 22 & 2.6 \\
\hline & $\begin{array}{l}\text { Falta de compro- } \\
\text { miso }\end{array}$ & 21 & 2.4 & $\begin{array}{l}\text { Descrei- } \\
\text { miento }\end{array}$ & 21 & 2.6 \\
\hline & Dinero & 21 & 2.4 & Desprestigic & 18 & 3.1 \\
\hline & Presidente & 16 & 1.6 & $\begin{array}{l}\text { Incompe- } \\
\text { tencia }\end{array}$ & 17 & 2.7 \\
\hline & Ideología & 16 & 2.1 & & & \\
\hline & Cambio & 16 & 2.4 & & & \\
\hline & Movilización & 15 & 2.5 & & & \\
\hline
\end{tabular}

Nota: fuente: elaboración propia 
Casa 3 o cuadrante inferior izquierdo, formado por las categorías: Compromiso, Política, Capacitación, Manipulación, Ideales, Protesta, Falta de compromiso, Dinero, Presidente, Ideología, Cambio y Movilización, corresponde a la zona de contraste, siendo los elementos menos frecuentes y al mismo tiempo muy importantes. En esta área se encuentran términos inferiores a la frecuencia media de evocación e inferiores a la media de los rangos medios de importancia calculada. Según Abric (2003, p. 64), esta configuración puede significar la existencia de subgrupos portadores de una representación diferente, cuyo núcleo estaría compuesto por uno o más elementos aqui presentes, es decir que podría considerarse como la estructura nuclear de la representación social de una minoría siendo al mismo tiempo un complemento de la primera periferia (Graca, Moreira \& Caballero, 2004; Oliveira et. al., 2005).

Casa 4 o cuadrante inferior derecho corresponde a la segunda periferia, — configurada por las categorías: Sociedad, Gobierno, Campańas, Lucha, Oportunismo, Honestidad, Descreimiento, Desprestigio e Incompetencia - siendo los elementos menos frecuentes y menos importantes (Abric, 2003; Roussiau \& Bonardi, 2001). En esta zona se ubican los términos inferiores a la frecuencia media de evocación y superiores a la media de los rangos medios de importancia estimada.

Segunda parte: donde se propone un listado de ítems, demandando la elección de aquellas categorías consideradas más características, más o menos características y menos características a la hora de describir al objeto representado, siendo las primeras potencialmente pertenecientes a la matriz nuclear y las segundas a la periferia.

En esta investigación, respetando el criterio de trabajar con múltiplos de tres (Vergés, 2001), se definieron 12 categorías del corpus total detectado con anterioridad, cinco correspondían al núcleo representacional, tres a la primera periferia y cuatro de la zona de contraste. Las ocho primeras fueron seleccionadas intencionalmente debido a su centralidad, mientras que las restantes fueron elegidas aleatoriamente debido a su carácter secundario, siendo ordenadas de manera indistinta con el propósito de corroborar su disposición y relevancia. 
En la primera instancia se requirió la elección de aquellas 4 primeras categorías concebidas como más importantes para describir al actor mencionado en una segunda instancia otras 4 menos importantes, quedando finalmente 4 sin elegir, las cuales adoptaron el carácter de medianamente importantes. De este modo, se considera que el peso respectivo de los términos en la representación es identificado indirectamente por el análisis de los reagrupamientos efectuados, en tanto este método pretende hacer emerger la jerarquía en cuestión incitando a los examinados a producirla directamente, mediante una serie de elecciones sucesivas por bloques (Abric, 2001). En síntesis, las etapas detalladas permiten confirmar la centralidad de los elementos correspondientes la representación examinada, tomando en cuenta las respuestas emitidas en relación con cada una de las alternativas categoriales implementadas, especialmente aquellas concentradas en la modalidad más caracteristicos (saliencia). Da Costa (2007) y Roland-Lévy (2003) recomiendan porcentajes cercanos o superiores al 50\% como valor confirmatorio.

\section{Procedimiento}

La participación de los individuos fue voluntaria y anónima, previo consentimiento informado. La aplicación del cuestionario fue colectiva. Para el cumplimiento de todos los objetivos, se efectuaron diversos análisis estadísticos mediante el auxilio del paquete estadístico SPSS-17 (Statistical Program for the Social Sciences).

\section{Resultados}

\section{Representaciones sociales del Dirigente político}

Componentes de las representaciones sociales

Los términos descriptores vinculados a la figura del Dirigente politico que se consideraron más característicos por los sujetos de la muestra fueron: Poder, Liderazgo, Representación y Corrupción. Asimismo los términos que se prefiguraron como más o menos característicos fueron: 
Presidente, Puntero, Dinero, Ambición y Mentira. Finalmente los términos que se contemplaron como menos característicos fueron: Guía, Ideales y Compromiso (Tabla 2). Cabe señalar que el puntero es un personaje informal asociado al clientelismo y a prácticas poco democráticas, el cual suele desenvolverse en barrios estableciendo un vínculo basado exclusivamente en la distribución de bienes materiales a cambio de favores (ejemplo votos) que redundan en un beneficio personal, de sus protegidos y/o de un sector ideológicamente afín.

\section{Tabla 2}

Caracterización componentes representaciones sociales del Dirigente politico

\begin{tabular}{lccc}
$\begin{array}{l}\text { REPRESENTACIONES SOCIALES } \\
\text { DIRIGENTE POLÍTICO } \\
\text { Términos descriptores }\end{array}$ & $\begin{array}{c}\text { Más } \\
\text { característico }\end{array}$ & $\begin{array}{c}\text { Más o menos } \\
\text { característico }\end{array}$ & $\begin{array}{c}\text { Menos } \\
\text { característico }\end{array}$ \\
\hline Poder & 60.3 & 29.9 & 9.7 \\
Liderazgo & 47.6 & 34.3 & 18.1 \\
Representación & 44.5 & 17.6 & 37.8 \\
Corrupción & 40.6 & 29.5 & 29.9 \\
Presidente & 20.4 & 64.5 & 15.1 \\
Puntero & 23.7 & 58.7 & 17.6 \\
Dinero & 29.5 & 44.1 & 26.5 \\
Ambición & 30.2 & 40.1 & 29.7 \\
Mentira & 28.3 & 36.4 & 35.3 \\
Guía & 9.3 & 38.1 & 52.7 \\
Ideales & 26.5 & 21.1 & 52.4 \\
Compromiso & 34.8 & 16.2 & 49.0 \\
\hline
\end{tabular}

Nota. Los valores presentados son porcentajes

Estructura factorial de las representaciones sociales

Con el propósito de analizar la forma en que se agrupaban los términos reportados se realizó un Análisis de Componentes Principales con rotación oblicua Promax como procedimiento de análisis multivariante. Se computó el índice de adecuación muestral propuesto por 
Kaiser-Meyer-Olkin (KMO) que proporcionó un coeficiente de .846, señalando que las matrices de datos eran aceptables para la realización del análisis y el Test de Esfericidad de Bartlett =1569.921, gl 36, $p<.000$, expresando un buen ajuste entre la cantidad de personas que habían respondido al instrumento y al número de ítems.

Se solicitó una estructura integrada por dos factores en respuesta al interés de reproducir los resultados empíricos encontrados anteriormente en torno a la temática.

Para delinear los conjuntos de los reactivos se decidió retener a aquellos elementos con saturaciones superiores a .350 en un factor (Costello \& Osborne, 2005). En base a la matriz aislada se anularon los términos descriptores Presidente, Poder y Ambición debido a que estos saturaban en más de un factor y la diferencia de saturación no era superior al 10\%, saturaban en un único factor y esta saturación era negativa, no saturaban en ninguno de los factores o bien no se integraban de forma teóricamente coherente con el resto de los términos pesquisados.

Como se exhibe en la Tabla 3, los factores preservados según el criterio de raíz latente explicaron respectivamente el $48.85 \%$ y el $10.90 \%$ de la varianza, siendo $59.75 \%$ la varianza total. Los reactivos integraron dos variables latentes dotadas de coherencia y con capacidad de ser analizadas a nivel teórico.

El primer factor concentró 5 términos descriptores: Compromiso, Ideales, Guía, Representación y Liderazgo, los cuales daban cuenta de Características y Aspectos del campo politico con una clara connotación Positiva, haciendo alusión a una concepción formal, teórica e ideal de la misma, por lo que se decidió denominarlo con aquella etiqueta. El segundo factor congregó a 4 términos descriptores: Corrupción, Mentira, Dinero y Puntero los cuales reflejaban Características y Aspectos políticos con un tinte eminentemente Negativo, relacionada con una concepción informal, práctica y real de la misma, recibiendo por lo tanto esta denominación a los fines de facilitar la lectura de los resultados y su interpretación. Cabe aclarar que si bien el penúltimo elemento representacional reportó una saturación inferior a la mínima contemplada, se optó por incluirlo en esta dimensión y confirmar su 
pertenencia a la misma mediante la implementación de otro tipo de técnica en el siguiente apartado.

Para vislumbrar la consistencia interna de los factores se calculó el coeficiente Alpha de Cronbach, obteniéndose índices de .73 para el Factor 1 y .72 para el Factor 2, corroborando de esta forma que el modelo factorial propuesto reportaba niveles óptimos de consistencia.

\section{Tabla 3}

Estructura factorial representaciones sociales del "Dirigente politico". Análisis de Componentes Principales, rotación Promax

\begin{tabular}{|c|c|c|}
\hline $\begin{array}{l}\text { REPRESENTACIONES } \\
\text { SOCIALES } \\
\text { DIRIGENTE POLÍTICO }\end{array}$ & $\begin{array}{c}\text { Factor } 1 \\
\text { Características/Aspectos } \\
\text { Políticos Positivos }\end{array}$ & $\begin{array}{c}\text { Factor } 2 \\
\text { Características/Aspectos } \\
\text { Políticos Negativos }\end{array}$ \\
\hline Compromiso & .81 & \\
\hline Ideales & .77 & \\
\hline Guía & .67 & \\
\hline Representación & .63 & \\
\hline Liderazgo & .43 & \\
\hline Puntero & & .85 \\
\hline Corrupción & & .50 \\
\hline Mentira & & .46 \\
\hline Dinero & & .30 \\
\hline Alpha & .73 & .72 \\
\hline Varianza Total & & \\
\hline Varianza Factor & $48.85 \%$ & $10.90 \%$ \\
\hline $\begin{array}{lr}\text { KMO } & .846 \\
\text { Bartlett } & x^{2}=1569.921\end{array}$ & $g l 36$ & $p=.000$ \\
\hline
\end{tabular}

Conglomerados jerárquicos de las representaciones sociales

Para complementar la información obtenida en base al Análisis de Componentes Principales precedente y explorar la estructura común existente entre los 9 términos descriptores de la figura del Dirigente 
político integrados a las dimensiones en cuestión, se realizó un análisis de conglomerados jerárquicos.

Para ello, se constituyó una matriz de distancias entre las variables estudiadas empleando como medida de similitud o proximidad entre las mismas un coeficiente Phi (cuatro puntos) (Brussino et al., 2012), a partir del cual tuvieron lugar distintos agrupamientos entre los constituyentes del campo de las representaciones sociales. El método de aglomeración utilizado fue el de vinculación inter-grupos o promedio, el cual que permitió aprovechar la información de todos los miembros de los conglomerados que se comparaban (Pardo \& Ruiz, 2002).

Tal como se deriva del análisis multidimensional, fue posible comprobar gráficamente a través de un dendograma la existencia de dos conglomerados distintos y alejados entre sí, similares a los factores subyacentes identificados por medio del procedimiento factorial.

El primer conglomerado se presenta integrado por los términos: Corrupción, Mentira, Dinero y Puntero, representando aspectos despreciables del ámbito político, mientras que el segundo conglomerado por los términos: Ideales, Guía, Compromiso, Representación y Liderazgo, representando aspectos valorados del mismo. Al interior del primer conglomerado, se evidencian de manera general dos grupos de palabras más cercanas entre sí, el primer grupo comprendido por: Corrupción, Mentira y Dinero y el segundo solo por Puntero, mientras que dentro del segundo conglomerado se prefigura en un grupo los términos Ideales, Guía, Compromiso y Representación y en otro solo el término: Liderazgo.

Diferencias en factores de las representaciones sociales según caracteristicas sociodemográficas y psicosociales

Con el propósito de verificar diferencias en los factores de las representaciones sociales según variables sociodemográficas y psicosociales se calcularon las pruebas $t$ de Student y análisis de varianza de una vía (ANOVA) con contraste posteriori Tuckey-b según corresponda.

Tal como se muestra en la Tabla 4, no se observan diferencias significativas en dichos factores en función de la edad, del sexo, la facultad y el tipo de disciplina de formación. 


\section{Tabla 4}

Diferencias en factores de las representaciones sociales del "Dirigente politico" de acuerdo a variables sociodemográficas

FACTORES REPRESENTA-

CIONES SOCIALES

VARIABLES SOCIODEMOGRÁFICAS

DIRIGENTE POLÍTICO

\begin{tabular}{|c|c|c|c|c|}
\hline Factores RS y Edad & $19-25$ años & $26-54$ años & $t$ & $g l$ \\
\hline $\begin{array}{l}\text { Características/Aspectos } \\
\text { Políticos Positivos (Factor 1) }\end{array}$ & 4.52 & 4.54 & -.073 & 429.471 \\
\hline $\begin{array}{l}\text { Características/Aspectos } \\
\text { Políticos Negativos (Factor 2) }\end{array}$ & 4.15 & 4.06 & .379 & 429.353 \\
\hline Factores $R S$ y Sexo & Mujeres & Varones & $t$ & $g l$ \\
\hline $\begin{array}{l}\text { Características/Aspectos } \\
\text { Políticos Positivos (Factor 1) }\end{array}$ & 4.54 & 4.45 & .245 & 429.403 \\
\hline $\begin{array}{l}\text { Características/Aspectos } \\
\text { Políticos Negativos (Factor 2) }\end{array}$ & 4.12 & 4.15 & -.097 & 429.462 \\
\hline
\end{tabular}

\begin{tabular}{lccccc}
\hline Factores RS y Facultad & Psicología & Filosofia Letras & $t$ & $g l$ & $p$ \\
\hline $\begin{array}{l}\text { Características/Aspectos } \\
\text { Políticos Positivos (Factor 1) }\end{array}$ & 4.65 & 4.34 & 1.091 & 429 & .138 \\
$\begin{array}{l}\text { Características/Aspectos } \\
\text { Políticos Negativos (Factor 2) }\end{array}$ & 4.00 & 4.31 & -1.398 & 429 & .082 \\
\hline
\end{tabular}

\begin{tabular}{lcccccc}
\hline Factores RS y Disciplina & $\begin{array}{c}\text { Pensamiento } \\
\text { Comportamiento } \\
\text { bumano }\end{array}$ & $\begin{array}{c}\text { Pedagó- } \\
\text { gicas }\end{array}$ & $\begin{array}{c}\text { Organi- } \\
\text { zación } \\
\text { social }\end{array}$ & $F$ & $g l$ & $p$ \\
\hline $\begin{array}{l}\text { Características/Aspectos } \\
\text { Políticos Positivos (Factor 1) }\end{array}$ & 4.65 & 4.13 & 4.36 & .639 & 430 & .264 \\
$\begin{array}{l}\text { Características/Aspectos } \\
\text { Políticos Negativos (Factor 2) }\end{array}$ & 4.00 & 4.87 & 4.26 & 1.487 & 430 & .114 \\
\hline Factores $R S$ y Año de cursado & Tercero & Cuarto & Quinto & $F$ & $g l$ & $p$ \\
\hline $\begin{array}{l}\text { Características/Aspectos } \\
\text { Políticos Positivos (Factor 1) }\end{array}$ & 4.65 & 4.12 & 4.86 & 2.583 & 430 & .039 \\
$\begin{array}{l}\text { Características/Aspectos } \\
\text { Políticos Negativos (Factor 2) }\end{array}$ & 4.05 & 4.52 & 3.75 & 4.436 & 430 & .006 \\
\hline
\end{tabular}


Se detecta una diferencia en el factor Características/Aspectos políticos Positivos entre los estudiantes que cursan el quinto año de su carrera y los estudiantes que cursan el cuarto año de la misma, a favor de los primeros.

Con relación al factor Características/Aspectos políticos Negativos se advierte una diferencia a favor de los alumnos que cursan el cuarto ańo de su carrera cuando se los compara con alumnos que cursan el quinto ańo de la misma.

Como se exhibe en la Tabla 5, se observa que los alumnos militantes en política universitaria se diferencian de los alumnos no-militantes en el factor Características/Aspectos políticos positivos, a favor de los primeros. En lo que se refiere al factor Características/Aspectos políticos negativos, hay una diferencia entre los estudiantes no implicados en prácticas proselitistas y los estudiantes involucrados en dicho tipo de prácticas, a favor de los primeros. Se identifica también una diferencia en el factor Características/Aspectos políticos positivos, a favor de los alumnos que reportan antecedentes de participación en política universitaria en comparación con los alumnos no poseedores de tales precedentes.

Con respecto al factor Características/Aspectos políticos negativos, se observa una diferencia entre los estudiantes que no poseen amigos/conocidos o parientes comprometidos con el ámbito político de la universidad y los estudiantes que si los poseen, favor de los primeros. No se detectan diferencias en los factores en función de la ocupación de cargos políticos de representación estudiantil universitaria, de la emisión del voto en elecciones de representantes estudiantiles universitarios y del conocimiento sobre la vida política universitaria. 


\section{Tabla 5}

Diferencias en factores de las representaciones sociales del "Dirigente politico" de acuerdo a variables psicosociales

FACTORES REPRESENTA-

CIONES SOCIALES

VARIABLES PSICOSOCIALES

DIRIGENTE POLÍTICO

\begin{tabular}{|c|c|c|c|c|c|c|}
\hline Factores RS y Militancia & $\begin{array}{l}\text { No-Mili- } \\
\text { tantes }\end{array}$ & \multicolumn{2}{|c|}{ Militantes } & $t$ & $g l$ & $p$ \\
\hline $\begin{array}{l}\text { Características/Aspectos } \\
\text { políticos positivos (Factor 1) }\end{array}$ & 4.44 & \multicolumn{2}{|l|}{5.81} & -2.380 & 429 & .009 \\
\hline $\begin{array}{l}\text { Características/Aspectos políti- } \\
\text { cos negativos (Factor 2) }\end{array}$ & 4.18 & \multicolumn{2}{|l|}{3.31} & 2.461 & 30.838 & .01 \\
\hline Factores $R S$ y Representación & $\begin{array}{l}\text { No-Repre- } \\
\text { sentantes }\end{array}$ & \multicolumn{2}{|c|}{ Representantes } & $t$ & $g l$ & $p$ \\
\hline $\begin{array}{l}\text { Características/Aspectos } \\
\text { políticos positivos (Factor 1) }\end{array}$ & 4.51 & \multicolumn{2}{|l|}{6.00} & -1.164 & 429 & .12 \\
\hline $\begin{array}{l}\text { Características/Aspectos } \\
\text { políticos negativos (Factor 2) }\end{array}$ & 4.14 & \multicolumn{2}{|l|}{3.20} & .933 & 429 & .18 \\
\hline Factores $R S$ y Votación & No-Votante. & \multicolumn{2}{|l|}{ Votantes } & $t$ & $g l$ & $p$ \\
\hline $\begin{array}{l}\text { Características/Aspectos } \\
\text { políticos positivos (Factor 1) }\end{array}$ & 5.00 & \multicolumn{2}{|l|}{4.50} & .847 & 429 & .19 \\
\hline $\begin{array}{l}\text { Características/Aspectos } \\
\text { políticos negativos (Factor 2) }\end{array}$ & 3.85 & \multicolumn{2}{|l|}{4.15} & -.662 & 429 & .25 \\
\hline Factores $R S$ y Antecedentes & $\begin{array}{c}\text { Sin antece- } \\
\text { dentes }\end{array}$ & \multicolumn{2}{|c|}{$\begin{array}{l}\text { Con antece- } \\
\text { dentes }\end{array}$} & $t$ & $g l$ & $p$ \\
\hline $\begin{array}{l}\text { Características/Aspectos } \\
\text { políticos positivos (Factor 1) }\end{array}$ & 4.17 & \multicolumn{2}{|c|}{4.75} & -2.061 & 429 & .02 \\
\hline $\begin{array}{l}\text { Características/Aspectos } \\
\text { políticos negativos (Factor 2) }\end{array}$ & 4.40 & \multicolumn{2}{|l|}{3.96} & 2.016 & 429 & .02 \\
\hline Factores $R S$ y Conocimiento $D$ & Desinformado & $\begin{array}{c}\text { Media- } \\
\text { namente } \\
\text { Informado }\end{array}$ & $\begin{array}{l}\text { Infor- } \\
\text { mado }\end{array}$ & $F$ & $g l$ & $p$ \\
\hline $\begin{array}{l}\text { Características/Aspectos } \\
\text { políticos positivos (Factor 1) }\end{array}$ & 4.55 & 4.59 & 4.47 & .076 & 430 & .46 \\
\hline $\begin{array}{l}\text { Características/Aspectos } \\
\text { políticos negativos (Factor 2) }\end{array}$ & 4.16 & 4.03 & 4.20 & .283 & 430 & .38 \\
\hline
\end{tabular}




\section{Cargos y Figuras políticas}

Indicadores de Cargos y Figuras politicas

Con el objetivo de detectar los Cargos/Figuras políticas que los estudiantes universitarios asociaban a la dirigencia considerada se recodificó a esta variable en 15 categorías independientes, a partir de las cuales fue posible encontrar que los personajes más mencionados por los estudiantes eran: Presidente de la Nación y Gobernador de la provincia. En proporciones inferiores fueron nombrados: el Puntero, el Diputado, el Intendente, el Concejal, el Presidente/Representante máximo de un partido político, el Legislador, el Dirigente sindical/gremial, el Delegado comunal, el Militante de un partido político, el Consejero universitario, el Presidente de Centro de estudiantes, el Representante máximo de un movimiento social y el Ministro en general (Tabla 6).

\section{Tabla 6}

Cargos y Figuras politicas mencionadas

\begin{tabular}{lccc}
\hline $\begin{array}{l}\text { CARGOS Y FIGURAS POLÍTICAS } \\
\text { Indicadores }\end{array}$ & Sí & No & $\begin{array}{c}\text { No } \\
\text { contesta }\end{array}$ \\
\hline Presidente de la Nación & 32.9 & 37.8 & 29.2 \\
Gobernador & 10.2 & 60.6 & 29.2 \\
Puntero & 5.6 & 65.2 & 29.2 \\
Diputado & 4.2 & 66.6 & 29.2 \\
Intendente & 3.5 & 67.3 & 29.2 \\
Concejal & 3.2 & 67.5 & 29.2 \\
Presidente/Representante máximo de partido político & 3.2 & 67.5 & 29.2 \\
Legislador & 2.6 & 68.2 & 29.2 \\
Dirigente sindical/gremial & 1.6 & 69.1 & 29.2 \\
Delegado comunal & 1.2 & 69.6 & 29.2 \\
Militante de partido político & 0.7 & 70.1 & 29.2 \\
Consejero universitario & 0.7 & 70.1 & 29.2 \\
Presidente de centro de estudiantes & 0.5 & 70.3 & 29.2 \\
Representante máximo de un movimiento social & 0.5 & 70.3 & 29.2 \\
Ministro & 0.2 & 70.5 & 29.2 \\
\hline
\end{tabular}

Nota. Los valores presentados son porcentajes 


\section{Tipos de Cargos y Figuras politicas}

Sintetizando la información detallada en el apartado anterior, se procedió a un agrupamiento de aquellos Cargos/Figuras políticas evocadas siguiendo 4 criterios:

- Criterio 1 (jurisdicción): ámbito o territorio sobre el cual los Dirigentes politicos ejercen las atribuciones y facultades que le corresponden. A partir de este criterio fue posible establecer una diferenciación entre: (a) Cargos/Figuras políticas exclusivamente nacionales, (b) Cargos/Figuras políticas exclusivamente locales (c) Cargos/Figuras políticas nacionales y/o locales.

- Criterio 2 (funciones): tipo de tareas que los Dirigentes politicos deben cumplir durante su desempeño. En base a este criterio fue posible una discriminación entre: (a) Cargos/Figuras políticas inherentes al Poder Ejecutivo (nacional, provincial, municipal), (b) Cargos/Figuras políticas inherentes al Poder legislativo (nacional, provincial, municipal), (c) Cargos/Figuras políticas inherentes a las organizaciones sociales, (d) Cargos/Figuras políticas inherentes a los partidos políticos y (e) Cargos/Figuras políticas inherentes al ámbito universitario.

- Criterio 3 (niveles de formalidad): característica propia del lugar que los Dirigentes politicos ocupan respecto a la estructura del sistema político tradicional/ convencional. A partir de este criterio fue posible establecer una diferenciación entre: (a) Cargos/Figuras políticas formales y (b) Cargos/Figuras políticas no formales.

- Criterio 4 (formas de elección): canales o procedimientos por medio de los cuales los Dirigente politicos se erigen como tales. En base este criterio fue posible una discriminación entre: (a) Cargos/ Figuras políticas elegidas de manera democrática e institucional y (b) Cargos/Figuras políticas no elegidas de manera democrática e institucional. 
Tal como se muestra en la Tabla 7, el ordenamiento efectuado permitió establecer — siguiendo el criterio 1-, que menos de la mitad de la muestra señala a personajes involucrados exclusivamente en la esfera nacional, mientras un poco menos a aquellos de carácter exclusivamente local y un porcentaje pequeño a los de índole nacional y/o local. De acuerdo al criterio 2, casi la mitad de los alumnos estudiados indica a actores vinculados con el Poder ejecutivo, siendo mucho menor los del Poder legislativo, los de organizaciones sociales, los de partidos políticos y los universitarios.

\section{Tabla 7}

Tipos de Cargos y Figuras politicas

\begin{tabular}{lccc}
\hline \multicolumn{1}{c}{$\begin{array}{c}\text { CARGOS Y FIGURAS POLÍTICAS } \\
\text { Tipos }\end{array}$} & Sí & No & $\begin{array}{c}\text { No con- } \\
\text { testa }\end{array}$ \\
\hline Criterio 1-Jurisdicción & & & \\
\hline Cargos y figuras políticas exclusivamente nacionales & 32.9 & 37.8 & 29.2 \\
Cargos y figuras políticas exclusivamente locales & 24.8 & 45.9 & 29.2 \\
Cargos y figuras políticas nacionales y/o locales & 13.0 & 57.8 & 29.2 \\
\hline Criterio 2- Funciones & & & \\
\hline Cargos y figuras políticas del Poder ejecutivo & 48.0 & 22.7 & 29.2 \\
Cargos y figuras políticas del Poder legislativo & 10.0 & 60.8 & 29.2 \\
Cargos y figuras políticas de organizaciones sociales & 7.7 & 63.1 & 29.2 \\
Cargos y figuras políticas de partidos políticos & 3.9 & 66.8 & 29.2 \\
Cargos y figuras políticas universitarias & 1.2 & 69.6 & 29.2 \\
\hline Criterio 3- Formalidad & & & \\
\hline Cargos y figuras políticas formales & 64.7 & 6.0 & 29.2 \\
Cargos y figuras políticas informales & 6.0 & 64.7 & 29.2 \\
\hline Criterio 4- Elección & 63.8 & 7.0 & 29.2 \\
\hline Cargos y figuras políticas electivos & 7.0 & 63.8 & 29.2 \\
\hline Cargos y figuras políticas no-electivos
\end{tabular}

Nota. Los valores presentados son porcentajes 
En base al criterio 3, más de la mitad de los participantes destacan a personajes pertenecientes al ámbito formal de la política en comparación con los pertenecientes al ámbito no formal. De igual manera, respetando el criterio 4, sobresalen los actores elegidos mediante la voluntad popular por vías institucionales válidas contra los no elegidos mediante esta vía.

\section{Diferencias en factores de representaciones sociales en función de Cargos/} Figuras politicas

Para determinar las diferencias en los factores de las representaciones sociales según los Cargos/Figuras políticas distinguidas a partir de los criterios precedentes, se llevó adelante una prueba $t$ de Student. En relación con el factor Características/Aspectos políticos Positivos se verifican diferencias, a favor de aquellos estudiantes que mencionan Cargos/Figuras políticas exclusivamente nacionales, universitarios, formales y elegidos por canales democráticos e institucionales (Tabla 8).

En lo que respecta al factor Características/Aspectos políticos Negativos se corroboran diferencias, a favor de los estudiantes que nombran Cargos/Figuras políticas exclusivamente locales, pertenecientes a organizaciones sociales, informales y no elegidos por vías democráticas e institucionales legítimas (Tabla 8). 


\section{Tabla 8}

Diferencias en factores de las representaciones sociales del "Dirigente politico" de acuerdo a Cargos/Figuras politicas (criterio-jurisdicción)

\begin{tabular}{lllllll}
\hline Representaciones Sociales según Cargos/Figuras & Sí & No & & $t$ & $g l$ & $p$ \\
\hline
\end{tabular}

Criterio - jurisdicción

Nacionales

Características/Aspectos Políticos Positivos

(Factor 1)

$\begin{array}{lllll}4.82 & 4.12 & -2.12 & 303 & .02\end{array}$

Características/Aspectos Políticos Negativos

(Factor 2)

$\begin{array}{lllll}3.70 & 4.51 \quad 3.20 \quad 303 & .001\end{array}$

Locales

Características/Aspectos Políticos Positivos

(Factor 1)

$\begin{array}{lllll}3.69 & 4.85 & 3.39 & 303 & .001\end{array}$

Características/Aspectos Políticos Negativos

(Factor 2)

$\begin{array}{lllll}4.79 & 3.78 & -3.84 & 303 & .000\end{array}$

Nacional y/o Local

Características/Aspectos Políticos Positivos

(Factor 1)

$\begin{array}{lllll}4.93 & 4.33 & -1.39 & 303 & .08\end{array}$

Características/Aspectos Políticos Negativos

(Factor 2)

$\begin{array}{lllll}3.98 & 4.17 & .57 & 303 & .29\end{array}$

Criterio - funciones

Poder ejecutivo

Características/Aspectos Políticos Positivos

(Factor 1)

$\begin{array}{lllll}4.39 & 4.56 & .49 & 303 & .31\end{array}$

Características/Aspectos Políticos Negativos

(Factor 2)

$\begin{array}{lllll}4.10 & 4.20 & .38 & 303 & .35\end{array}$

Poder legislativo

Características/Aspectos Políticos Positivos

(Factor 1)

$\begin{array}{lllll}4.81 & 4.38 & -.91 & 303 & .18\end{array}$

Características/Aspectos Políticos Negativos

(Factor 2)

$\begin{array}{lllll}4.02 & 4.15 & .35 & 303 & .36\end{array}$

Partidos políticos

Características/Aspectos Políticos Positivos

(Factor 1)

$\begin{array}{lllll}4.71 & 4.43 & -.46 & 18.87 & .33\end{array}$

Características/Aspectos Políticos Negativos (Factor 2)

$\begin{array}{llll}3.76 & 4.16 \quad .92 & 19.57 \quad .19\end{array}$




\begin{tabular}{llllllll}
\hline Representaciones Sociales según Cargos/Figuras & Sí & No & & $t$ & & $g l$ & $p$ \\
\hline
\end{tabular}

Organizaciones sociales

Características/Aspectos Políticos Positivos (Factor 1)

\section{$\begin{array}{lllll}3.85 & 4.51 & 1.25 & 303 & .11\end{array}$}

Características/Aspectos Políticos Negativos (Factor 2)

$\begin{array}{lllll}4.85 & 4.05 & -1.96 & 303 & .03\end{array}$

Figuras universitarias

Características/Aspectos Políticos Positivos (Factor 1)

$\begin{array}{lllll}6.60 & 4.41 & -1.67 & 303 & .05\end{array}$

Características/Aspectos Políticos Negativos (Factor 2)

$\begin{array}{lllll}3.00 & 4.15 & 1.15 & 303 & .13\end{array}$

Criterio-formalidad

Figuras formales

Características/Aspectos Políticos Positivos $\quad \begin{array}{lllll}4.54 & 3.38 & -1.96 & 303 & .03\end{array}$

(Factor 1)

Características/Aspectos Políticos Negativos $\quad \begin{array}{lllll}4.05 & 5.08 & 2.28 & 303 & .01\end{array}$

(Factor 2)

Figuras no formales

$\begin{array}{llllll}\text { Características/Aspectos Políticos Positivos } & 3.38 & 4.54 & 1.96 & 303 & .03\end{array}$

(Factor 1)

Características/Aspectos Políticos Negativos $\quad \begin{array}{lllll}5.08 & 4.05 & -2.28 & 303 & .01\end{array}$ (Factor 2)

Criterio-elección

Figuras electivas

Características/Aspectos Políticos Positivos $\quad \begin{array}{lllll}4.54 & 3.53 & -1.82 & 303 & .04\end{array}$

(Factor 1)

$\begin{array}{llllll}\text { Características/Aspectos Políticos Negativos } & 4.05 & 4.90 & 1.99 & 303 & .02\end{array}$

(Factor 2)

Figuras no electivas

$\begin{array}{llllll}\text { Características/Aspectos Políticos Positivos } & 3.53 & 4.54 & 1.820 & 303 & .04\end{array}$

(Factor 1)

$\begin{array}{llllll}\text { Características/Aspectos Políticos Negativos } & 4.90 & 4.05 & -1.99 & 303 & .02\end{array}$

(Factor 2) 


\section{Discusión}

Los hallazgos del estudio revelan una representación de los estudiantes universitarios acerca de los dirigentes políticos caracterizada por la convivencia de elementos nucleares opuestos tales como Liderazgo y Representación versus Poder y Corrupción, los cuales son los encargados de determinar las significaciones y el ordenamiento correspondientes al resto de las nociones incluidas en este particular universo. Estos resultados apoyan la idea sostenida por Moscovici (1994), quien intentando explicar la pluralidad/variabilidad figurativa sugiere la existencia de texturas, las cuales aluden a la de la posibilidad de ajuste del campo representacional a una multiplicidad de sentidos, aspecto que también es señalado por Moliner (2007), al referirse al carácter polisémico que revisten los contenidos centrales de la representación. En efecto, según Rodríguez Cerda y colaboradores (2001) este tipo de configuración simbólica, a partir de su núcleo como punto de referencia, debe ser pensada en términos no unívocos o lineales, sino fundamentalmente diversos y plurales.

Las significaciones contrapuestas mencionadas ratifican una fuerte ruptura localizada también en otras muestras juveniles de la región latinoamericana (Fernández, 2000) entre lo que los políticos en calidad de representantes son y hacen actualmente (el ser) — plano correspondiente a las disfunciones en el desempeño de sus tareas, donde se inscribe el incumplimiento, la mentira, el beneficio propio y el alejamiento de la comunidad y desconocimiento de sus necesidades-, y aquello que estos representantes debieran ser y hacer (el deber ser) - plano inherente a su rol efectivo y tradicional donde rigen valores democráticos como la justicia, la solidaridad, la equidad entre otros- , pasando el fin de este distanciamiento por un cambio en el primer plano, sustentado en los valores sobre los que se construye el segundo.

En coincidencia con los datos obtenidos en el análisis realizado en base a las categorías, en la estructura representacional se identificaron dos dimensiones latentes de naturaleza contrapuesta, ilustradas por los factores Características/Aspectos Políticos Positivos versus Características/ 
Aspectos Políticos Negativos, en torno a las cuales se dispusieron la totalidad de componentes. Asimismo, se detectaron dos conglomerados, que arrojaron agrupamientos categoriales disímiles y distantes entre sí —el primero sugiriendo facetas positivas y el segundo facetas negativas del mundo político-, próximos a los factores subyacentes encontrados por medio del procedimiento factorial.

Las facetas detalladas se asemejan a los hallazgos de estudios previos que destacan la existencia de una representación social de la política de corte divergente basada en una epistemología dialógica y dialéctica (Marková, 2000), en tanto compuesta por ideas, categorías, conceptualizaciones y evaluaciones en conflicto, vinculadas por relaciones de oposición, pero no necesariamente de exclusión. Algunas de ellas tienen un sentido personalizado, funcional, práctico e informal, cercanas a la experiencia cotidiana, la mala política o lo que la política es, y otras con un sentido abstracto, normativo, teórico y formal, cercanas al ideal, la buena política o lo que la política debería ser. La mixtura de elementos simbólicos, reflexivos o conceptuales y elementos reales, empíricos, o incongruentes en el universo representacional político, recuerda justamente que el mismo resulta de la unión entre símbolos y funciones, por lo es posible indicar un terreno que congrega dos visiones alternativas pero no excluyentes en la apropiación del objeto y en la consecuente toma de posición respecto al mismo, una valorada que requiere ser reforzada y otra devaluada a combatir tal como se declaró arriba (Capozza, Robusto \& Busseto, 1999; González Pérez et al., 2006; Catellani \& Quadrio, 1991; Rodríguez Cerda et. al,. 2001, 2007).

De manera coincidente en su investigación primigenia acerca del saber de sentido común sobre la teoría psicoanalítica, Moscovici (1961) convalidó la dinámica coexistencia de diferentes modalidades de pensamiento, producto de las relaciones entre el hombre y su medio ambiente, denominando a este estado como polifasia cognitiva. A partir del mismo, es posible identificar — como en esta pesquisa de la política- la convivencia simultánea de una variedad contradictoria e incompatible de conceptos, imágenes y significados, los que reflejan la forma en que 
los grupos sociales, o las sociedades y culturas, conceptualizan diversos objetos, siendo esperables, por lo tanto, diferencias manifiestas en estos sistemas de conceptualización a nivel intra e inter-grupal.

Con relación a las dimensiones representacionales de la dirigencia política, no se detectaron diferencias en función de la edad, del sexo, la facultad, el tipo de disciplina de formación, la ocupación de cargos políticos de representación estudiantil universitaria, la emisión del voto en elecciones de representantes estudiantiles universitarios, y del conocimiento sobre la vida política universitaria. Respecto al factor Características/Aspectos políticos Positivos se encontraron diferencias a favor de los estudiantes que cursaban el quinto año de su carrera, de los militantes estudiantiles en política universitaria y de aquellos sujetos de la muestra que poseían antecedentes — parientes y/o amigos conocidos- involucrados en política dentro de la Universidad.

En lo que hace al factor Características/Aspectos políticos Negativos se observaron diferencias a favor de los estudiantes que cursaban el cuarto ańo de su carrera, de los no militantes estudiantiles en política universitaria y de los sujetos que no poseían antecedentes de participación en política universitaria. Esta información se adscribe en la línea de resultados correspondientes a estudios locales previos (Torres Stöckl \& Arué, 2013; Torres Stöckl \& Carreras, 2010) que dan cuenta de cómo los jóvenes próximos a finalizar sus estudios superiores, implicados en el ejercicio de prácticas de militancia estudiantil y socializados en un ambiente familiar y/o de pares en el que se estima la actividad política, reportan una mirada más preciada y valorada del estrato dirigencial, mientras que quienes no cuentan con estas particularidades mantienen una concepción contraria. Asimismo, la tendencia es también consistente con otras investigaciones que verifican la relevancia de las pertenencias y posicionamientos grupales diferenciales, confirmando la vigencia de criterios discrepantes en torno al significado del objeto, producto del esfuerzo y del trabajo artesanal de diferentes colectivos para acceder a problemáticas sociales de este estilo (Brissaud-Le Poizat \& Moliner, 2004; Catellani, 1993; Geka, 2003; Larrue, Bonardi \& Roussiau, 2000; Rodríguez Cerda et al., 1997, 2007, Wachelke \& Hames, 2009). 
A pesar de los matices de anclaje detectados, cabe destacar que pocas de las características s ociodemográficas y psicosociales tomadas en consideración arrojaron diferencias, alineándose con la tendencia advertida en pesquisas anteriores (Bruno, Barreiro \& Kriger, 2010, 2011; Bruno \& Castorina, 2012; Cárdenas, et al., 2007; Yepez Hernández, 2003) en donde se avizoró una vivencia más bien trasversal a las diversas categorías de jóvenes. Esta vivencia permitiría pensar en una representación social con un matiz marcadamente dominante y hegemónico, que dejaría entrever que el paso por la institución universitaria, el cual no siempre resulta una instancia demasiado decisiva en la configuración, modificación y diversificación de las representaciones de la política del estudiantado.

Finalmente, los cargos/figuras más asociados a la clase dirigente por los participantes del estudio fueron: el Presidente de la Nación y el Gobernador de la provincia. Considerando los criterios de agrupación implementados se destacaron aquellos personajes implicados exclusivamente en la esfera nacional, el Poder ejecutivo, el ámbito formal de la política y los elegidos mediante la voluntad popular y por vías institucionales válidas.

En torno al factor Características/Aspectos políticos Positivos, se determinaron diferencias a favor de los Cargos/Figuras políticas exclusivamente nacionales, universitarios, formales y elegidas por canales democráticos e institucionales. Respecto del factor Características/ Aspectos políticos Negativos, se apreciaron diferencias a favor de Cargos/ Figuras políticas exclusivamente locales, pertenecientes a organizaciones sociales, informales y no elegidas por vías democráticas e institucionales legítimas. Este resultado demuestra una encarnación de los componentes representacionales y sus dimensiones más favorables en actores políticos dotados de mayor envergadura, nivel jerárquico y legalidad, con los que los universitarios entablan una relación atravesada por idealización, mientras que los componentes y dimensiones representacionales desfavorables se remiten a actores políticos de menor importancia, categoría y licitud visualizados por los participantes en un sentido más concreto. Como lo corroboran otros trabajos llevados a cabo con población 
juvenil en Argentina (Bruno \& Barreiro, 2014), la política se prefigura remitida predominantemente a la actividad pública desempeñada por los políticos, así como al espacio ocupado por diversas instituciones del Estado, por lo que podría pensarse que a pesar del desprestigio que esta actividad padece de manera generalizada a nivel social, la población examinada apuesta aún de manera contrastante a apoyarla en su vertiente democrática e institucional.

De lo desarrollado precedentemente, se ha verificado que la política como concepto central en y para la vida social cubre un espectro que merece especial interés y dedicación científica, ya que cada sociedad desarrolla representaciones propias sobre este aspecto, las que, junto a las condiciones estructurales, definen las posibilidades de conocimiento y de acción política (Villarroel, 2003).

La representación funciona como un sistema de interpretación de la realidad que regula las relaciones que los individuos establecen con su entorno físico y social, determinando sus comportamientos y prácticas (Abric, 2001). En esta dirección, conocer la serie de categorías, concepciones y nociones presentes en el espacio público que en este caso los estudiantes universitarios incorporan a su repertorio, así como los mecanismos y contenidos que operan de acuerdo a sus grupos de pertenencia y referencia, puede resultar una fuente de explicación de cómo estos se enfrentan, acercan y adentran en tales dominios (Nateras Domínguez et al., 1999), mediante el ejercicio de prácticas o modalidades de participación política que encuentran arraigo tanto dentro como fuera de la Universidad. Se rescata entonces, el valor instrumental de la teoría de las representaciones sociales en el estudio de la esfera política, entendiendo que la imagen de cualquier personaje político esta es una impresión global que construyen los ciudadanos en la dinámica de la comprensión de los asuntos públicos, siendo este un factor determinante para la orientación de su comportamiento político. (González Navarro et al., 2004).

Desde esta perspectiva simbólica — centrada en la caracterización de las formas de pensamiento vigentes - este estudio se propuso realizar un aporte relevante a la comprensión de aquellos sentidos comunes y 
divergentes que se tejen en el vínculo que los miembros de una sociedad entablan con la vida pública, propia de sistemas políticos democráticos altamente heterogéneos y contradictorios (Almond \& Verba 1963), contribuyendo de esta forma a la evaluación de su calidad (Rodríguez Cerda et al., 1999) en términos de posibilidades y limitaciones (Wagner \& Hayes, 2011). Se considera necesario el desarrollo de futuras investigaciones que permitan perfeccionar esta perspectiva de abordaje, a nivel teórico y metodológico, así como ampliar las observaciones realizadas sobre el comportamiento de las variables en consideración, las cuales posibilitarán sin dudas profundizar el conocimiento sobre el saber social y el posicionamiento de la juventud contemporánea en relación con la arena política para desde allí generar propuestas orientadas a potenciar su fundamental involucramiento y participación en ella, en tanto ciudadanos.

\section{Referencias}

Abric, J. C. (1971). Experimental study of group creativity : Task representation, group structure and performance. European journal of social psychology, 1, 311-326

Abric, J. C. (1976). Jeux, Conflits et representations sociales, these D'Etat. Marsella: Université de Provence.

Abric, J. C. (1993). Central system, Peripherical system. Their functions and roles in dynamics of social representations. Papers on social representations. Textes sur les représentantions sociales, 2(2), 75-78.

Abric, J. C. (2001). Prácticas sociales y representaciones. México: Coyoacán.

Abric, J. C. (2003). La recherche du noyau central et de la zone muette des représentations sociales. En J. C., Abric (Ed.), Méthodes d' étude des Représentations Sociales (pp. 59-80). Paris: Eres.

Almond, G. \& Verba, S. (1963) The Civic Culture. Political Attitudes and Democracy in Five Nations. Newbury Park, CA: SAGE Publications. 
Banchs, M. A. (1994). Desconstruyendo una desconstrucción: lectura de Ian Parker (1989) a la luz de los criterios de Parker y Shotter (1990). Papers on Social Representations, 3(1), 52-74.

Boudon, R. \& Bourricaud, F. (1994). Dictionnaire Critique de la Sociologie. París: PUF.

Bourdieu, P. (1976). Entwurfeiner Theorie der Praxis. Frankfurt: Suhrkamp.

Bourdieu, P. (1992). Economía das trocas simbólicas. Sao Paulo: Estúdio. Braud, P. (1991). El jardin de las delicias de la democracia. México: FCE. Brissaud-Le Poizat, A. \& Moliner, P. (2004). Représentation sociale et système de catégorie: le cas des hommes politiques. Les cahiers internationaux de psychologie sociale, 64, 13-20.

Bruno, D. Barreiro, A. \& Kriger, M. (2010). Las representaciones sociales de la politica y la creencia en un mundo justo en estudiantes secundarios de la ciudad autónoma de Buenos Aires. Resultados preliminares. Ponencia presentada en el V Congreso Marplatense de Psicología. Facultad de Psicología Universidad Nacional de Mar del Plata-Argentina.

Bruno, D., Barreiro, A. \& Kriger, M. (2011). Representaciones sociales de la política en los jóvenes: Corrupción institucional y mentira. Kairos: Revista de Temas Sociales, 28, 1-16.

Bruno, D. \& Barreiro, A. (2014). La política como representación social. Psicología Politica, 48, 69-80.

Bruno, D. \& Castorina, A. (2012). La democracia en el nivel medio: representaciones sociales y su relación con el nivel educativo de los padres. Resultados preliminares. Ponencia presentada IV Congreso Internacional de Investigación y Práctica Profesional en Psicología XIX Jornadas de Investigación y VIII Encuentro de Investigadores en Psicología del Mercosur. Facultad de Psicología de la Universidad de Buenos Aires-Argentina.

Brussino, S., Imhoff, D. \& Gutierrez, J. (2012) Categorías cognitivas sobre 'lo político' en jóvenes cordobeses/as. Actualidades en Psicología, 26, 87-107. 
Camino, L., Lima, M. E. O. \& Torres, A. R. R. (1997). Ideologia e espaço político em estudantes universitarios. En L. Camino, L. Lhullier \& S. A. Sandoval (Orgs.), Estudos sobre comportamento politico (pp. 87-105). Florianópolis: Letras Contemporâneas.

Capozza, D., Robusto, E. \& Busseto, G. (1999). Représentation sociale du leadership. Papers on social representations, 8, 11-18.

Cárdenas, M., Parra, L., Picón, J., Pineda, H. \& Rojas, R. (2007). Las representaciones sociales de la política y la democracia. Última Década, 26, 53-78.

Catellani, P. \& Quadrio, A. (1991). Ideal and real in representation of politics. Revue internationale de Psychologie sociale, 4, 231-255.

Catellani, P. (1993). Reference to semantic aspects of social representations in solving problemas. Papers on social representations, 2(2), 107-114.

Costello, A. \& Osborne, J. (2005). Best practices in exploratory factor analysis: four recommendations for getting the most from your analysis. Practical Assessment. Research and Evaluation, 10, 1-9.

Da Costa, T. (2007). A representacoes sociais acerca das pessoas como HIV/ AIDS entre enfermeiros: un estudo da zona muda (Tesis de Licenciatura). Universidad del estado de Rio de Janeiro, Brasil.

De Rosa A.S. (1987). The social representatíns of mental illness in children and adults. En W. Doise \& S. Moscovici (Eds.), Current issues in social psychology (pp. 47-113). Cambridge: Cambridge University Press.

Diamond, L. (1994). (Editor) Political Culture and Democracy in Developing Countries. Boulder: Lynne Rienner Publishers.

Doise, W. (1993). Debating social representations. En G. M. Breakwill $\&$ D. V. Canter (Orgs.), Empirical approaches to social representations (pp. 157-170). London: Academic Press.

Fernández, G. (2000). Notas sobre la participación política de los jóvenes chilenos. En S. Balardini, (Ed.), La participación politica $y$ social de los jóvenes en el horizonte del nuevo siglo (pp. 87-108). Buenos Aires: Clacso. 
Flament, C. (1994). Aspects périphériques des représentations sociales. En C. Guimelli (Org.), Structures et transformations des représentations sociales (pp. 85-118). Neuchâtel: Delachaux et Niestlé.

Flament, C. (1987). Practiques et représentations sociales. En J. L. Beauvois, R. V. Joule \& J. M. Monteil (Eds.), Perspectives cognitives et conduites sociales. I. Théories implicites et conflits cognitifs (pp. 143-150). Cousset: Del Val.

Flament, C. (2001). Estructura, dinámica y transformación de las representaciones sociales. En J. C., Abric (Comp.), Representaciones y prácticas sociales (pp. 33-52). México: Coyoacán.

Geka, M. (2003). Penser le rapport des jeunes à la politique: une étude de valeurs et de représentations sociales (Tesis doctoral). École des Hautes Études en Sciences Sociales, Paris.

González Navarro, M., Garduño Olvera, H., Cruz Coronel, R., Flores Luna, D. \& Viveros Calderón, S. (2004). El dictamen de la ciudadanía en el D. F. en torno a las figuras de Vicente Fox y Manuel López Obrador. En S. Arciga Bernal (Ed.), Del pensamiento social a la participación: estudios de Psicología social en México (p. 181). México: Sociedad Mexicana de Psicología social.

González Pérez, M. A. (2006) Pensando la politica: Representación socialy cultura politica en jóvenes mexicanos. México D. F: Plaza y Valdez.

Graça, M. M., Moreira M. A. \& Caballero C. (2004). Representaçóes sobre a matemática, seu ensino e Aprendizagem: um estudo exploratório. Investigacoes em Ensino de Ciencias, 9(1), 37-93.

Gramsci, A. (1987). Los intelectuales y la organización de la cultura. Buenos Aires: Nueva Visión.

Grizé, J. B, Vergés, P. \& Silem, A. (1987) Salariés face aux nouvelles technologies. París: CNRS Éditions.

Guimelli, C. (1988). Agression idéologique, prattques nouvelles et transformation progressive d'une représentation sociale. Marsella: Université de Provence.

Habermas, J. (1992). Further reflections on the public sphere. En C. Calhoun (Ed.), Habermas and the Public Sphere (pp. 421-461). Cambridge, Massachusetts: The MIT Press. 
Jodelet, D. (1989). Représentations sociales: un domaine en expansión. En D. Jodelet (Dir.), Les représentations sociales (pp. 47-48). París: PUF.

Jovchelovitch, S. (2000). Corruption flows in our blood: mixture and impurity in representations of public life in Brazil. En M. Chaib \& B. Orfali (Eds.), Social Representations and Communicative Processes (pp. 139-155). Jönköping: Jönköping University Press. Jovchelovitch, S. (2001). Social representations, public life and social construction. En K. Deauz \& G. Philogéne (Eds.), Representations of the social. Oxford: Blackwell.

Larrañaga, M. Valencia, J. \& Vergés, P. (2007). Representaciones sociales y desempleo. En T. Rodríguez Salazar \& M. L, García Curiel (Coords.), Representaciones sociales: teoria e investigación (pp. 311-328). México: Universidad de Guadalajara.

Larrue, J., Bonardi, Ch. \& Roussiau, N. (2000). Étude des liens entre plusieurs objets de représentations sociales. Anuario de Psicologia, 31(3), 19-37.

Lozada Santeliz, M. (2000). El otro es el enemigo. Representaciones sociales e imaginarios sociales en tiempos de polarización: el caso de Venezuela. En A. Arruda \& M. de Alba (Coords.), Espacios imaginarios y Representaciones sociales (pp. 381-406). Aportes desde América Latina. España: Anthropos.

Marková, I. (2000). Amédée or how to get rid of it: social representations from a dialogical perspective. Culture and Psychology, 6, 419-460.

Mendoza, R. \& Camino, L. (2000). Configuración del espacio político. El caso de los estudiantes brasileños. Psicología Política, 21, 7-29.

Moliner, P. (1994). Les méthodes de repérage e d'identification du noyau des représentations sociales. En C. Guimelli (Ed.), Structures et transformations des représentations sociales (pp. 199-232). Lausanne, Switzerland: Delachaux et Niestlé.

Moliner, P. (2007). La teoría del núcleo matriz de las representaciones sociales. En T. Rodríguez \& M. L. García (Eds.), Representaciones 
sociales. Teoria e investigación (pp. 137-157). Guadalajara: Universidad de Guadalajara-México.

Moscovici, S. (1961). La psychanalyse, son image, son public. París: Presse Universitaire de France.

Moscovici, S. (1988). Notes toward a description of social representations. European Journal of social Psychology, 18, 211-250.

Moscovici, S. (1994). Social representation and pragmatic communication. Social Sciencie Information, 33(2), 163-177.

Moscovici, S. \& Marková, I. (2003). La presentación de las representaciones sociales: diálogo con Serge Moscovici. En J. A. Castorina (Comp.), Las representaciones sociales. Problemas teóricos y conocimientos infantiles (pp. 111-152). Barcelona: Gedisa.

Mugny, G. \& Carugati F. (1985). Lintelligence au pluriel: les représentations sociales de l'intellígence et de son développement. Cousset: DelVal.

Nateras Domínguez, J. O., Mendoza Romero, A. \& Angulo Reyes, Y. (1999). La democracia en infantes: génesis d una representación social. Polis. Investigación y análisis sociopolitico y psico-social, 99, 67-99.

Oliveira; D. C., Marques S. C., Gomes, M. T \& Teixeira, M. C. T. V. (2005). Analise das evocacoes libres: uma técnica de análise estrutural das representaçóes sociais. En A. S. P. Moreira, B. V. Camargo, J. C. Jesuíno \& S. M. Nóbrega (Eds.), Perspectivas teórico-metodológicas em representaçóes sociais (pp. 573-603). UFPB: Joao Pessoa.

Pardo, A. \& Ruíz, M.A. (2002). SPSS 11. Guía para el análisis de datos. Madrid: McGraw-Hill.

Rodríguez Cerda, O., Díaz Rojas, F. \& Mendoza Romero, A. (1997). Entre los adversarios de una sociedad: la política y la justicia. Estudio del pensamiento social. Polis, 96(1), 139-177.

Rodríguez Cerda, O., Cadena Herrera, C. A., Saldívar Moreno, D.M. \& Mendoza Romero, A. (1999). Representación social de la democracia: de lo ideal a lo real. Polis, 98, 33-55. 
Rodríguez Cerda, O., Buendía Reséndiz, M.L. \& Aguilera Arango, A.M. (2001). Representación social de la democracia: un estudio del anclaje. Polis, 00, 151-170.

Rodríguez Cerda, O. \& Ayala García, S. (2007). Representación social de la democracia: Las creencias sobre el bien común. Versión estudios en comunicación y politica, 19, 73-89.

Rodríguez Salazar, T. (2002). Representar para actuar, representar para pensar. Breves notas metodológicas. En C. Palacio (Comp.), Comunicación, cultura y politica (pp. 25-30). Guadalajara: Editorial CUCSH-UdeG.

Roland-Lévy, C. (2003). Genesis and Evolution of the Representations of the Euro. Ponencia presentada en Euro-Workshop (IAREP), Vienna, Austria.

Roussiau, N. \& Bonardi, C. (2001). Les représentations sociales. État des lieux et perspectives. Belgique: Mardaga.

Spini, D. (1997). Valeurs et représentations sociales des droits de l'homme: Une approche structurale (Tesis doctoral inétdita). Ginebra: Universidade de Genebra.

Torres Stöckl, C. \& Arué, R. (2013). El mundo de la política y su concepto de acuerdo a militantes estudiantiles universitarios en Tucumán. Revista polis. Investigación y análisis sociopolítico y psicosocial, 9(1), 109-137.

Torres Stöckl, C. \& Carreras P. (2010). Imágenes y sentidos de la política en estudiantes de la Universidad Nacional de Tucumán. Cuaderno de H ideas, 4(4), 100-121.

Vergés, P. (1992). L'évocation de l'argent: une méthode pour la definition du noyau central d'une représentation. Bulletin de psychologi, 405(XLV), 203-209.

Vergés, P. (1995). Représentations sociales partagées, périphériques, indifférentes, d'une minorité: méthodes d'approche. Les cahiers internationaux de psycologie sociale, 28, 77-95.

Vergés, P. (2001). L'analyse des représentations sociales par questionnaires. Revue française de sociologie. 42, 537-561. 
Villarroel, G. (2001). Las representaciones politicas del venezolano. Caracas: Consejo de Desarrollo Científico y Humanístico.

Villarroel, G. (2003). Paradojas de la democracia en Venezuela. Dualidad y conflicto en las representaciones y en la política actual. Espacio Abierto, 12(1), 63-93.

Villarroel, G., Brito, M. \& De Armas, E. (2004). Representaciones sociales sobre la libertad y la igualdad en estudiantes venezolanos. Revista Venezolana de Economía y Ciencias Sociales, 10(2), 181193.

Villarroel, G. \& De Armas, E. (2005). Desprecio por la política: aproximación a las representaciones sociales de estudiantes venezolanos. Politeia, 38(34-35), 11-18.

Wachelke, J. \& Hames, I. (2009). Representaçóes sociais sobre politica segundo posicionamento político na campanha eleitoral de 2006. Psicologia em Estudo, 14(3), 519-528.

Wachelke, J. (2012). Representaciones sociales: una revisión de la teoría y las investigaciones desde el enfoque estructural. Universitas Psycologica, 11(3), 729-741.

Wagner, W., Duveen, G., Verna, J. \& Themel, T. (2000). I have some faith and at the same time I don't believe in it. Cognitive poliphasia and cultural change. Journal of Community and Applied Social Psychology, 10(4), 301-314.

Wagner, W. \& Hayes, N. (2011). El discurso de lo cotidiano y el sentido común: La teoria de las representaciones sociales. España: Anthropos.

Yepez Hernández, M. (2003). Representaciones sociales de democracia en estudiantes universitarios de la UNAM. En N. P. Maldonado Reynoso (Coord.), Investigación de la comunicación. México en los albores del siglo XXI (pp. 123-139). Recuperado de http://www. researchgate.net/publication/27392315_Representaciones_sociales_de_democracia_en_estudiantes_universitarios_de_la_UNAM

Recibido: 24 de junio, 2014 Aceptado: 11 de agosto, 2014 